\title{
A comparison of competitive intelligence activities in Brazil, Malaysia, Morocco and South Africa
}

\author{
Authors: \\ Adeline S.A. du Toit ${ }^{1}$ \\ Nisha Sewdass ${ }^{1}$ \\ Affiliations: \\ ${ }^{1}$ Department of Information \\ Science, University of Pretoria, \\ South Africa \\ Correspondence to: \\ Adeline du Toit \\ Email: \\ adeline.dutoit@up.ac.za \\ Postal address: \\ Department of Information \\ Science, University of \\ Pretoria, Pretoria 0002, \\ South Africa \\ Dates: \\ Received: 16 Oct. 2013 \\ Accepted: 26 Feb. 2014 \\ Published: 03 June 2014 \\ How to cite this article: \\ Du Toit, A.S.A. \& Sewdass, \\ N., 2014, 'A comparison of \\ competitive intelligence \\ activities in Brazil, Malaysia, \\ Morocco and South Africa', \\ Acta Commercii 14(1), Art. \\ \#234, 7 pages. http://dx.doi. \\ org/10.4102/ac.v14i1.234

\section{Copyright:} \\ (C) 2014. The Authors. \\ Licensee: AOSIS \\ OpenJournals. This work \\ is licensed under the \\ Creative Commons \\ Attribution License.
}

Orientation: This article compared competitive intelligence activities in Brazil, Malaysia, Morocco and South Africa.

Research purpose: The purpose was to determine how these countries can use competitive intelligence to increase their competitiveness in the global economy.

Motivation for the study: Competitive intelligence is a challenge in developing economies.

Research design, approach and method: A questionnaire survey was sent to competitive intelligence professionals in the four study countries.

Main findings: The most important primary information source used in all four countries is direct customer feedback and the most important secondary information source used is corporate websites. Companies in all four countries did not use advanced analysis techniques.

Practical/managerial implications: It is recommended that all four countries should develop a competitive intelligence culture by creating awareness of competitive intelligence amongst their employees.

Contribution/value added: It is crucial to apply competitive intelligence in the four countries in order to become more competitive in the global economy.

\section{Introduction}

The economic success of a country depends on its capacity to apply activities which create a competitive advantage, its ability to create an environment of transformation and progress and its capacity to innovate (Canongia 2006:58). Competitive intelligence (CI) has long been recognised as a strategic management tool that could enhance competitiveness. This perception of $\mathrm{CI}$ as a strategic tool is not exclusively for use in developed economies - CI is expected to play a key developmental role in developing economies as well. The need to enhance companies' and, by extension, countries' competitiveness has grown rapidly (Hart \& Spero 1997). $\mathrm{CI}$ is essential and will increasingly be a challenge in the years to come, especially for emerging economies (Canongia 2006:58; Kalinowski 2012:11).

This article will compare CI activities in Brazil, Malaysia, Morocco and South Africa. Companies in these four countries are facing increased environmental uncertainty as a result of the challenges of the global economy and there is an increasing need to compete globally and to monitor and understand the environment more accurately for survival and success (Kalinowski 2012:14). 'With the recognition that competitive challenges and risks will increase significantly in the future, there is an increasing need to continuously monitor the competitive landscape to remain competitive' (Heppes 2006:43). Little research (Dou, Dou \& Manullang 2005; Du Toit 2003) has been done regarding the application of CI in developing economies. The purpose of this article is thus to examine the current situation with regard to CI activities in the four above-mentioned countries. Companies in these countries tend to be less dynamic and more resistant to change, compared with companies in industrialised countries (Hawkins 2004:42-52).

Competitiveness is a multifaceted concept and, according to Garelli (2003:702), the competitiveness of nations 'focuses on the policies implemented by nations to shape the environment around enterprises' and economic value is only created within the context of an enterprise. Garelli (2003:702) defines competitiveness as 'the manner in which companies are trying to create and develop a unique comparative advantage'. According to Waheeduzzaman (2002:13), the ultimate goal of competitiveness is to improve the standard of living or real income of the citizens of a country. Competitiveness is the capacity of a company to work more productively and effectively in relation to a similar company (Hart \& Spero 1997). 
Competitiveness, however, also relates to factors such as efficient markets and the ability to harness the benefits of existing technologies, as well as business sophistication (Blanke 2007). Since companies actually compete in the global economy, many authors are of the opinion that when studying competitiveness, the focus should be on companies since they are 'the main engines of a country's competitiveness' (Garelli 2003:704). According to Gilad (2011:4), a company's competitiveness is 'determined by its level of strategic decision-making generated by intelligence gleaned to secure its position in changing markets'.

As globalisation increases, it has serious implications for developing economies since the growing interdependencies between national economies accelerate the process of economic integration in the knowledge economy (Postelnicu \& Ban 2010:54). With the globalisation of markets, the need to enhance companies' and countries' competitiveness has grown rapidly. If government supports and encourages the application of $\mathrm{CI}$, then it would have a more positive impact on the economy of a country and the quality of life for its citizens.

\section{Competitive intelligence}

With the increased volatility of the business environment (the business environment is highly complex, with a vast number of potentially relevant influences), both countries and companies rely on early detection of environmental changes through the use of environmental scanning so that they may respond with appropriate counter measures (Viviers, Muller \& Du Toit 2005:252). Since a company requires time to adapt to the changing environment it should have the ability to anticipate environmental changes and imagine the consequences of alternative responses to those changes and then use CI to identify potential opportunities and threats (Viviers, Muller \& Du Toit 2005:253). Because CI improves decision making, it helps a company to meet or exceed its objectives and business goals. Companies in developing economies who are familiar with CI practices in local regional markets may find the requirement to extend CI practices globally very difficult to accomplish in a structured way (Du Toit \& Strauss 2010:18; Kalinowski 2012:12). Executives are expected to study several reports and proposals before making decisions and it is often found that these executives are overwhelmed with information and lack intelligence to allow interpretation of the information provided and the appropriate response (Kalinowski 2012:12). Gilad (2001:21-23) states that intelligence is neither data nor information collection but is used to 'identify and manage risks', where such risks are generated by changes in the company's external environment. It can, therefore, be said that the companies that are able to turn information into intelligence will succeed (Sewdass 2012:4).

There are many definitions of CI. Kahaner (1996:16) defines CI as 'a systematic programme for gathering and analysing information about competitors' activities and general business trends to further the company's goals'.
Calof and Wright (2008:717) regard CI as being 'a system of environmental scanning which integrates the knowledge of everyone in the company'. Johnson (2004) indicates that ' $\mathrm{CI}$ is understanding what is about to happen and being reactive about the result with some form of reliable accuracy'. According to Dou et al. (2005), CI is 'the process of developing actionable foresight regarding competitive dynamics and non-market factors that can be used to enhance competitive advantage'. CI is concerned with the techniques used to select and filter information from a variety of sources, to interpret and analyse it, to communicate it to the right people and to use it effectively. Competitive dynamics refers to the moves and countermoves of competitors, suppliers, customers, alliance partners and potential competitors. Non-market factors (eg. government regulations, tariffs, culture of a country) have an impact on competitive dynamics, 'but are not suppliers of products or services to the industry' (Prescott 1999:42-43). CI uses legally- and ethically-available public information sources to assess the strengths and weaknesses of its competitors. The global nonprofit membership organisation, Strategic and Competitive Intelligence Professionals (SCIP) (2013), has devised a code of ethics to raise CI ethical standards. Murphy (2005:51) notes that ' $[t]$ he SCIP code demands higher standards of conduct than required by the law'. An employee contacting a competitor and misrepresenting himself or herself to get vital information is an example of unethical behaviour, which is not conducted legally in the context of CI.

\section{Competitive intelligence in developing countries}

Kahaner (1996:25) states that CI can be used as a way to win economic wars. According to Calof and Skinner (1999:21), a country will underperform without an appropriate CI infrastructure and they quote Prescott and Gibbons, saying that the key question is not whether governments should play a role in a company's CI efforts but what should be the purposes and methods used by government'. Hawkins (2004:51) emphasises that companies in developing economies should use formal processes of collecting, analysing and disseminating intelligence to successfully compete in the global economy. Managers in developing economies continue to be surprised by unexpected changes in the environment because they do not conduct environmental scanning. It thus appears that the advances with regard to managing intelligence are, to date, largely unknown in these countries (Pellissier \& Kruger 2011). Currently, most developing economies are only weakly integrated with the global economy since their national cultures do not necessarily value information and intelligence (Viviers, Saayman \& Muller 2005:577). The use of CI will enable companies in developing economies to gain a greater market share over time and to compete successfully against their international competitors (Pellissier \& Kruger 2011:10). Ifan et al. (2004:995) state that 'after a period of recession and inflation, most developing countries have to face the necessity of improving their capacities to innovate and increase the competitiveness of their industries'. Furthermore, in developing economies, the creation of new products from their natural resources is 
important as it has the ability to contribute to the country's foreign direct investment (Dou et al. 2005). In order to compete in the global economy, developing economies should apply CI.

\section{Research method and design Design}

Since CI is a relatively new activity in developing economies, this study is mainly exploratory in nature (Fishwick 2005:274). It attempts to provide a comparison of the implementation of $\mathrm{CI}$ in four developing economies, namely Brazil, Malaysia, Morocco and South Africa. A questionnaire survey methodology was used where questionnaires were administered to CI professionals in companies in these countries. A combination of convenience sampling and snowball sampling was used in order to identify the CI professionals. Convenience sampling refers to the procedure of obtaining respondents (units or people) who are most conveniently available (Zikmund 2003:367). Snowball sampling, in turn, refers to procedures in which additional respondents are secured from information provided by initial respondents. This technique is used to locate members of rare populations by referrals (Cooper \& Schindler 2007:425). CI practices in all four countries are still in the early phase of development and when CI is practised by individuals in companies, it is still a matter of sensitivity (Decaup \& Domingues 2009:25; Strauss \& Du Toit 2010:311). Furthermore, in all of the countries under study, there is no available and recognised list of practising CI professionals. For this reason, the researchers had to rely on their personal contacts and networks in the various industries in order to identify the CI professionals. These professionals were assumed to have a sound knowledge of $\mathrm{CI}$, as well as its implementation and benefits for companies. This is a limitation of this study, since because a complete list of CI professionals in the four countries was not available, some important CI professionals may have been omitted unintentionally from the survey. Another limitation is that the four countries where the survey was conducted were chosen by random selection.

\section{Procedure}

The questionnaire was structured as follows: Section A: Background and demographic information; Section B: Competitive situation in companies; Section C: Competitive intelligence implementation in companies. The questionnaire was sent as an attachment via email and was accompanied by a cover letter to all identified respondents. The completed questionnaires had to be returned to the researchers by email. In Brazil, the questionnaires were emailed to $33 \mathrm{CI}$ professionals; 13 questionnaires were completed, representing a response rate of $39.3 \%$. In Malaysia, the questionnaires were emailed to $80 \mathrm{CI}$ professionals and 42 respondents completed the questionnaires, representing a response rate of $52.5 \%$. In Morocco, the questionnaires were emailed to $40 \mathrm{CI}$ professionals and 25 questionnaires were completed, representing a response rate of $62.5 \%$, whilst in South Africa, the questionnaires were emailed to $40 \mathrm{CI}$ professionals and
24 questionnaires were completed - a response rate of $60 \%$. As explained in the previous paragraph, a complete list of CI professionals was not available for the chosen countries and the findings can thus not be generalised.

\section{Results Biographical data}

In Brazil, the gender of the respondents was almost equal (53.8\% men; $46.2 \%$ women), whilst in Malaysia, $62 \%$ of the respondents were men and 38\% were women. In Morocco and South Africa, most of the respondents were male $(71 \%$ in Morocco and 70\% in South Africa). In Brazil, Malaysia and Morocco, the majority of respondents were younger than 50 years old (Brazil 84.6\%, Malaysia 90.5\% and Morocco 92\%), whilst in South Africa, only half of the respondents were younger than 50 years (50\%). This means that although CI is growing rapidly in South Africa, it lacks the highly-skilled young people required to drive the process into the future. The majority of respondents in Brazil (38\%) and Malaysia (40.5\%) have bachelor's degrees whilst in Morocco and South Africa, CI professionals are more skilled (50\% with a Master's degree in Morocco and 30\% with an honours degree in South Africa). CI professionals in all four countries were either in the top management or senior-/middle-management level of their companies (69\% in Brazil, 79\% in Malaysia, 66\% in Morocco and 85\% in South Africa). This means that in South Africa more respondents are in senior positions in their companies than in the other countries. According to Figure 1, the majority of the respondents in Brazil (31\%) and Malaysia $(15 \%)$ are in the manufacturing industry, whilst in Morocco, the majority of the respondents $(16 \%)$ are in the construction industry. In South Africa, the majority of the respondents $(25 \%)$ are in financial, insurance, real estate and business services.

\section{Competitive situation}

In Brazil (46\%) and South Africa (55\%), the majority of the respondents are of the opinion that they cope above average

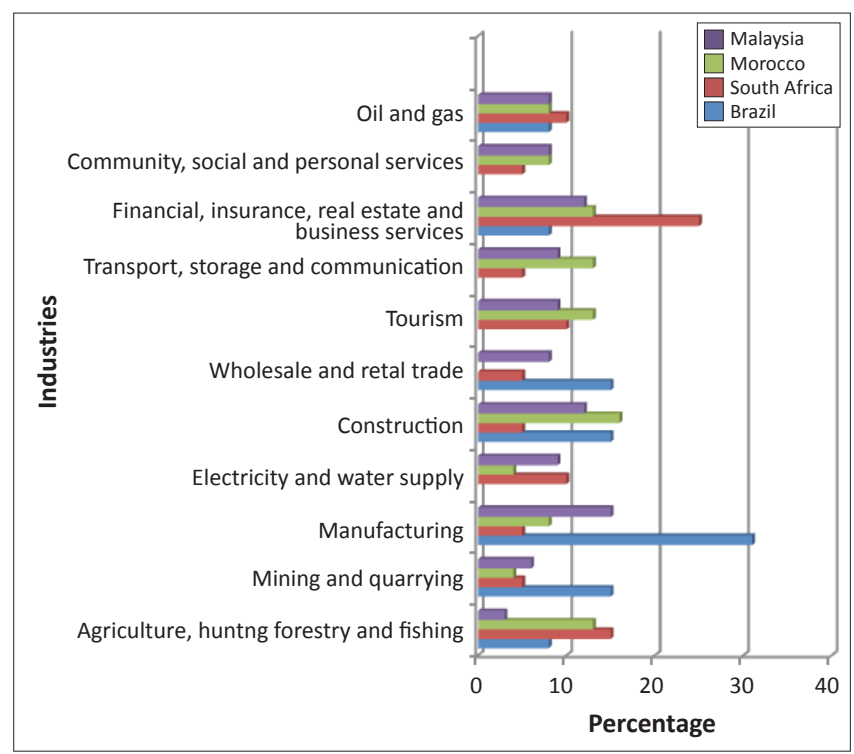

FIGURE 1: Industries represented by the respondents in this study. 
with changes in the business environment. This, however, is not the situation in Malaysia (23.8\%) and Morocco (13\%), where fewer respondents are of the opinion that they cope well with changes in the business environment. This is an indication that companies in these two countries should pay more attention to $\mathrm{CI}$ as a strategic business tool and that the companies do not realise the importance of scanning the environment as an early-warning tool which would allow them to adapt their strategies. The majority of respondents in Morocco (42\%) and South Africa (65\%) indicated that competition in their business environment is very intense, compared with Brazil and Malaysia where only $23 \%$ and $36 \%$, respectively, of the respondents indicated that competition is very intense.

\section{Competitive intelligence function and/or unit}

According to the majority of respondents in South Africa (60\%), a formal CI function did exist in their companies. In Brazil, a formal CI function existed at only $15 \%$ of the respondents' companies and in companies in Malaysia and Morocco, only 35\% and 33\%, respectively. In South Africa, the $\mathrm{CI}$ function had been in existence for more than five years in $85 \%$ of the respondents' companies. This is not, however, the situation in the other countries, where only $8 \%$ of the Brazilian respondents' companies had included a CI function for more than five years and only $21 \%$ in both Malaysia and Morocco. This indicates that the CI function is more mature in South Africa than in the other countries.

\section{Competitive intelligence activities}

Respondents were asked to indicate the five most important CI activities in their companies (28 activities were listed). With regard to the five most important $\mathrm{CI}$ activities implemented, respondents in all four countries used CI to quantify and/or qualify strategic choices (Brazil 62\%, Malaysia 36\%, Morocco $44 \%$ and South Africa 21\%) (Figure 2). Brazil is the only country where $\mathrm{CI}$ is linked to the strategic objectives of the respondents' companies (54\% of the respondents), South Africa is the only country where $8 \%$ of the respondents interviewed managers to verify intelligence products and Malaysia is the only country where respondents used CI as a continuous activity (7\%) and where CI alerted managers to issues that were not on the agenda.

\section{Use of secondary information sources}

Information on regulatory bodies is used annually by respondents in Brazil (38\%) and quarterly in both Malaysia $(45 \%)$ and South Africa (35\%) (see Table 1 for the five most important secondary information sources used in each country [ 15 sources were listed]). The fact that information on regulatory bodies is so important is an indication that restrictive regulations (enacted by the government) often contributed to a decline in competitiveness. This is in contrast with developed economies where deregulation enhances competitiveness (Dou et al. 2005). Promotional material is an important information source for respondents, being used weekly in Brazil (38\%) and quarterly in both Malaysia (43\%) and South Africa (20\%). Of interest is that respondents in Morocco listed some secondary information sources not used by respondents in the other countries, for example, exhibitions/road shows/trade shows (40\% of the respondents used these annually), customer demographics ( $32 \%$ of the respondents used these quarterly), trade journals ( $28 \%$ of the respondents used these daily) and information on potential business partners ( $24 \%$ of the respondents used this

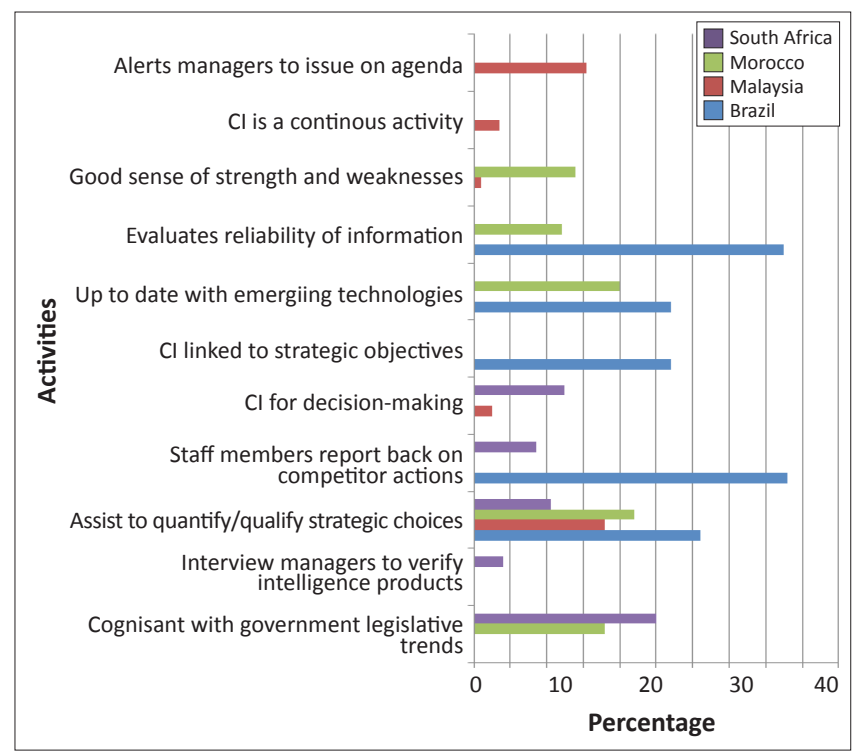

$\mathrm{Cl}$, competitive intelligence.

FIGURE 2: The five most important competitive intelligence activities listed by country.

TABLE 1: The five most important secondary sources used by the respondents in this study.

\begin{tabular}{|c|c|c|c|c|c|c|c|c|c|c|c|c|c|c|c|c|c|c|c|c|}
\hline \multirow[t]{2}{*}{ Secondary source } & \multicolumn{5}{|c|}{ Brazil (\%) } & \multicolumn{5}{|c|}{ Malaysia (\%) } & \multicolumn{5}{|c|}{ Morocco (\%) } & \multicolumn{5}{|c|}{ South Africa (\%) } \\
\hline & 1 & 2 & 3 & 4 & 5 & 1 & 2 & 3 & 4 & 5 & 1 & 2 & 3 & 4 & 5 & 1 & 2 & 3 & 4 & 5 \\
\hline Corporate websites & 23 & 23 & 23 & 23 & 8 & 24 & 48 & 7 & 21 & 0 & 8 & 24 & 0 & 17 & 8 & 30 & 4 & 20 & 20 & 15 \\
\hline Customer demographics & - & - & - & - & - & - & - & - & - & - & 8 & 3 & 24 & 32 & 8 & - & - & - & - & - \\
\hline $\begin{array}{l}\text { Exhibitions/Road shows/Trade } \\
\text { shows }\end{array}$ & - & - & - & - & - & - & - & - & - & - & 12 & 0 & 18 & 12 & 40 & - & - & - & - & - \\
\hline $\begin{array}{l}\text { Information on potential business } \\
\text { partners }\end{array}$ & - & - & - & - & - & - & - & - & - & - & 24 & 24 & 15 & 23 & 8 & - & - & - & - & - \\
\hline Internal financial information & 31 & 8 & 23 & 15 & 23 & 10 & 24 & 38 & 21 & 7 & - & - & - & - & - & 10 & 30 & 20 & 20 & 10 \\
\hline Promotional material & 38 & 23 & 23 & 23 & 8 & 11 & 11 & 21 & 43 & 4 & - & - & - & - & - & 10 & 30 & 15 & 20 & 15 \\
\hline Sales forecasts & 23 & 15 & 23 & 38 & 0 & - & - & - & - & - & - & - & - & - & - & - & - & - & - & - \\
\hline Survey summaries & - & - & - & - & - & 0 & 7 & 10 & 38 & 31 & - & - & - & - & - & 4 & 15 & 25 & 25 & 20 \\
\hline Trade journals & - & - & - & - & - & - & - & - & - & - & 28 & 12 & 24 & 4 & 18 & - & - & - & - & - \\
\hline
\end{tabular}

1, Daily; 2, Weekly; 3, Monthly; 4, Quarterly; 5, Annually. 
weekly). Corporate websites are an important information source for respondents in all four countries: Brazilian respondents (23\%) accessed this resource daily, weekly, monthly and quarterly, Malaysian (48\%) and Moroccan (24\%) respondents weekly and South African respondents $(30 \%)$ used them daily.

\section{Primary information sources used}

The most important primary information source used in all four countries (see Table 2; 12 primary information sources listed) is direct customer feedback and it is collected daily by respondents in Brazil (46\%), Malaysia (55\%), Morocco (33\%) and South Africa (28\%). This indicates that all of the respondents prefer to collect their own information directly from customers. Two other important information sources used by respondents in all four countries are industry experts and suppliers. Information from industry experts is collected weekly in Brazil (31\%) and Malaysia (30\%), monthly in Morocco (28\%) and daily, monthly and quarterly in South Africa (25\%). Information from suppliers is collected daily in both Brazil (46\%) and South Africa (28\%), whilst in Malaysia $35 \%$ of the respondents collected this information annually. In Morocco, this information is collected monthly by $33 \%$ of the respondents. Analysis of competitor feedback is not one of the five most important primary information sources in South Africa, whilst employees attending conferences and seminars is (only in South Africa) one of the five most important information sources. This indicates that South African respondents sensitise and train their employees to collect information on the competitive environment.

\section{Analytical methods or models used}

Twenty-six analytical methods and models were listed in the questionnaire and respondents were instructed to select the five methods most used by themselves (Figure 3). SWOT (Strengths, Weaknesses, Opportunities and Threats) analysis is one of the five most important analytical methods or models used by respondents in Brazil (23\%), Malaysia (10\%) and South Africa (10\%); and competitor analysis is one of the five most important analytical methods or models used by respondents in Brazil (15\%), Malaysia (55\%) and South Africa $(15 \%)$. Financial analysis and valuation is one of the five most important analytical methods used by respondents in Brazil $(23 \%)$, Malaysia (14\%) and Morocco $(28 \%)$, whilst financial ratio and statement analysis is one of the five most important analytical methods used by respondents in Brazil (31\%), Malaysia (14\%) and Morocco (25\%). Customer segmentation analysis is one of the five most important analytical methods used by respondents in Brazil (23\%) and Morocco (22\%), benchmarking is one of the five most important analytical methods used by respondents in Morocco (28\%) and South Africa (15\%), gap analysis one of the five most important analytical methods used by respondents in Morocco (18\%) and South Africa (15\%), whilst industry analysis is one of the five most important analytical methods used by respondents in Malaysia (62\%) and South Africa (50\%).This means that none of the respondents in all four countries use advanced analysis techniques, for example, psychological profiling or on-line data screening, to interpret information.

\section{Methods used to distribute and present competitive intelligence findings}

Figure 4 provides information on the five most important methods used by respondents in the four countries to distribute and present CI findings (12 methods were listed). 'E-mails', 'presentations' and 'reports' are some of the five most important methods used by respondents in all four countries. 'Customer/competitor/supplier profiles' is one of the five most important methods used by respondents in

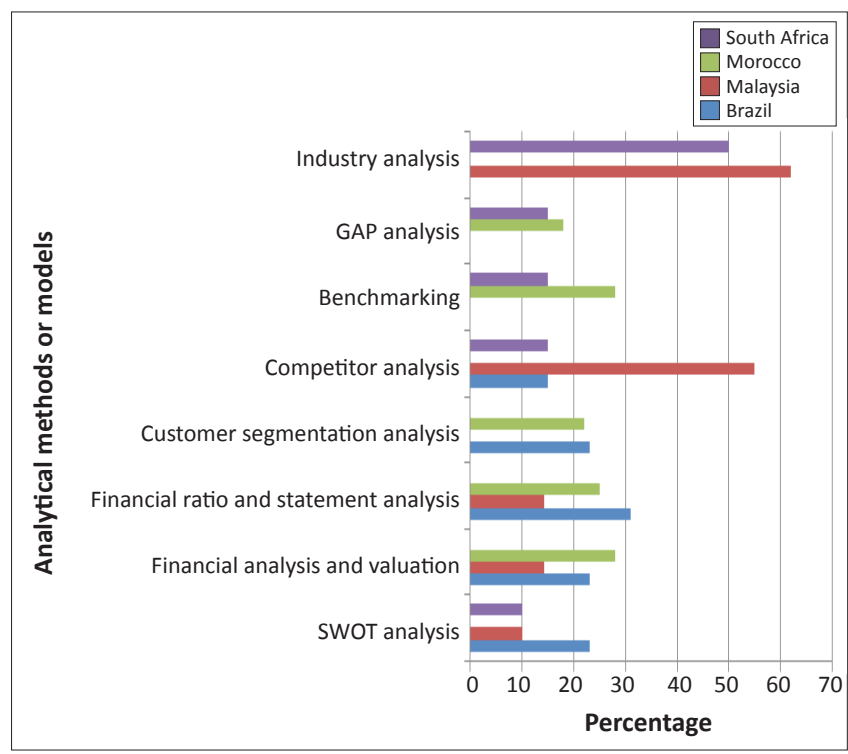

SWOT, Strengths, Weaknesses, Opportunities, Threats.

FIGURE 3: The five analytical methods or models most used by the respondents in this study.

TABLE 2: The five most important primary sources used by the respondents in this study.

\begin{tabular}{|c|c|c|c|c|c|c|c|c|c|c|c|c|c|c|c|c|c|c|c|c|}
\hline \multirow{2}{*}{ Primary source } & \multicolumn{5}{|c|}{ Brazil (\%) } & \multicolumn{5}{|c|}{ Malaysia (\%) } & \multicolumn{5}{|c|}{ Morocco (\%) } & \multicolumn{5}{|c|}{ South Africa (\%) } \\
\hline & 1 & 2 & 3 & 4 & 5 & 1 & 2 & 3 & 4 & 5 & 1 & 2 & 3 & 4 & 5 & 1 & 2 & 3 & 4 & 5 \\
\hline Analysis of competitor's products & 0 & 23 & 38 & 0 & 23 & 0 & 0 & 55 & 25 & 20 & 4 & 4 & 28 & 12 & 24 & - & - & - & - & - \\
\hline Company employees & - & - & - & - & - & - & - & - & - & - & - & - & - & - & - & 45 & 15 & 15 & 10 & 5 \\
\hline Direct customer feedback & 46 & 8 & 15 & 15 & 8 & 55 & 20 & 10 & 5 & 5 & 33 & 8 & 33 & 8 & 0 & 28 & 28 & 20 & 10 & 0 \\
\hline Industry experts & 0 & 31 & 15 & 15 & 23 & 20 & 30 & 20 & 10 & 20 & 4 & 0 & 17 & 28 & 24 & 25 & 20 & 25 & 25 & 5 \\
\hline Sales staff & 38 & 15 & 23 & 8 & 8 & 40 & 20 & 15 & 5 & 20 & 21 & 4 & 25 & 12 & 12 & - & - & - & - & - \\
\hline $\begin{array}{l}\text { Employees attending conferences } \\
\text { and seminars }\end{array}$ & - & - & - & - & - & - & - & - & - & - & - & - & - & - & - & 0 & 10 & 28 & 40 & 10 \\
\hline Suppliers & 46 & 15 & 8 & 15 & 8 & 10 & 15 & 20 & 20 & 35 & 21 & 0 & 33 & 8 & 8 & 28 & 10 & 25 & 10 & 10 \\
\hline
\end{tabular}

1, Daily; 2, Weekly; 3, Monthly; 4, Quarterly; 5, Annually. 


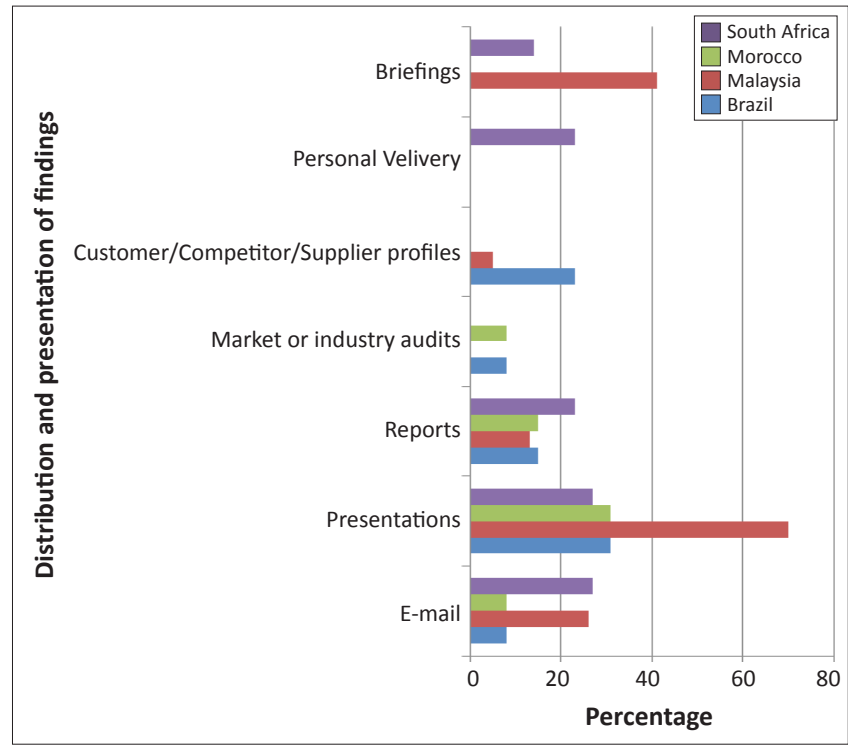

FIGURE 4: The five methods most used to distribute and present competitive intelligence findings.

Morocco (23\%) whilst 'personal delivery' is important only in South Africa (23\%). 'Market or industry audits' is one of the five most important methods used by respondents in Brazil (8\%) and Morocco (8\%); 'customer/competitor/ supplier profiles' is one of the five most important methods used by respondents in Brazil (23\%) and Malaysia (5\%); and 'briefings' is one of the five most important methods used by respondents in Malaysia (41\%) and South Africa (14\%).

\section{Conclusion and recommendations}

According to Dou et al. (2005), government, universities and companies should collaborate since it is the intersection of the three entities that will encourage innovation and economic growth. As Brazil, Malaysia, Morocco and South Africa become more integrated into the global economy it stands to reason that the global economy will have more of an impact on these countries' economies. To this end, it has become crucial to monitor global events and trends as it is very important for these countries to develop a CI culture. Companies should have an appropriate organisational awareness of CI and a culture of competitiveness. It is also recommended that companies in the four countries should enhance a CI culture by creating CI awareness amongst employees and providing CI training sessions to new employees. In companies, there should be a high degree of organisational consciousness with regard to creating a culture of competitiveness and the gathering of information should be the responsibility of all employees. There are clear indications that the world will become more competitive. Whether CI professionals in the four developing economies will meet these challenges is not clear and, according to the empirical survey conducted, few have actual plans to improve their ability to keep track of competitors and to enhance their competitiveness. Few respondents conduct $\mathrm{CI}$ in a formal systematic manner and CI professionals should strategically manage their activities so as to improve CI within companies. CI should assist senior management in the development and review of a set of key intelligence needs (KINs). Only a limited number of respondents recognise the importance of a $\mathrm{CI}$ unit and none of the respondents indicated the use of $\mathrm{CI}$ for decision-making as being one of the five most important $\mathrm{CI}$ activities. CI should assist senior management in developing and reviewing a set of KINs. In order to provide direction to the CI function within these companies, it is important that they interview management on a regular basis. According to the survey, none of the respondents in the four countries being studied used sophisticated techniques such as blindspot analysis and scenario analysis to analyse their CI data. The use of these techniques as early-warning signals is very important with regard to getting a head-start on competitive companies in the global economy. The CI function in companies should thus evolve from 'providing just the facts' (reactive) to being 'a key component of company strategy' (proactive). It is recommended that companies seek to engage proactively with the global environment by revising their strategic priorities. It is, therefore, evident that companies need to redress some critical competitiveness issues, most notably the establishment of the CI function as a strategic tool. Without a CI strategy, companies will find it difficult to position themselves in the global marketplace.

A limitation of this research is that a small sample was used and the findings can therefore not be generalised; further research which includes a larger sample will have to be conducted. It is recommended that the survey should be conducted in all developing economies. In the light of the worldwide interest in $\mathrm{CI}$ in developing economies and the desire to understand how Brazil, Malaysia, Morocco and South Africa can improve their competitiveness, the hope is expressed that the governments and companies of these countries will, in future, create an environment which will facilitate the competitiveness of companies and encourage long-term sustainability.

\section{Acknowledgements Competing interests}

The authors declare that they have no financial or personal relationship(s) which may have inappropriately influenced them in writing this article.

\section{Authors' contributions}

Both A.S.A.d.T. (University of Pretoria) and N.S. (University of Pretoria) contributed equally to the writing of this article.

\section{References}

Blanke, J., 2007, 'Assessing Africa's competitiveness in a global context', viewed 01 April 2014, from http://blogafrica.allafrica.com/download/resource/main/main/ idatcs/00011144:883f2d7de4239ae9ec571dcfaa422e3c.pdf

Calof, J. \& Skinner, B., 1999, 'Government's role in competitive intelligence: What's happening in Canada?', Competitive Intelligence Magazine 2(2), 20-23.

Calof, J.L. \& Wright, S., 2008, 'Competitive intelligence: a practitioner, academic and inter-disciplinary perspective', European Journal of Marketing 42(7/8), 717-730. $\mathrm{http}: / / d x . d o i . o r g / 10.1108 / 03090560810877114$ 
Canongia, C., 2006, 'Synergy between competitive intelligence ( $\mathrm{Cl})$, knowledge management (KM) and technological foresight (TF) as a strategic model of prospecting - the use of biotechnology in the development of drugs against breast prospecting - the use of biotechnology in the development of drugs against breast
cancer', Biotechnology Advances 25(1), 57-74. http://dx.doi.org/10.1016/j. cancer', Biotechnology

Cooper, D.R. \& Schindler, P.S., 2007, Business research methods, 10th edn., McGrawHill, New York, NY.

Decaup, A. \& Domingues, F., 2009, 'Competitive intelligence practices implementation in Brazilian companies', Competitive Intelligence Magazine 12(3), 20-25.

Dou, H., Dou Jr., J-M. \& Manullang, S.D., 2005, 'The magic triangle - how to develop and apply competitive intelligence in developing countries', viewed 15 November 2013, from http://isdm.univ-tln.fr/PDF/isdm22/isdm22 dou.pdf

Du Toit, A.S.A., 2003, 'Competitive intelligence in the knowledge economy: what is in it for South African manufacturing enterprises?', International Journal of Information Management 23(2),111-120. http://dx.doi.org/10.1016/S02684012(02)00103-2

Du Toit, A.S.A. \& Strauss, A.C., 2010, 'Competitive intelligence and Africa's competitiveness: what's happening in South Africa?' Mousaion 28(2), 17-32.

Fishwick, K., 2005, 'The role of competitive intelligence in the global automotive supply chain', in D.L. Blenkhorn \& C.S. Fleisher (eds), Competitive intelligence and global business, pp. $\mathrm{x}-\mathrm{xx}$, Praeger Publishers, Westport, CT.

Garelli, S, 2003, 'Competitiveness of nations: the fundamentals', in IMD World Competitiveness Yearbook, pp. 702-713, International Institute for Management Development, Lausanne, Switzerland.

Gilad, B., 2001, 'Industry risk management: Cl's next step', Competitive Intelligence Magazine 4(3), 21-27.

Gilad, B., 2011, 'Strategy without intelligence, intelligence without strategy', Business Strategy Series 12(1), 4-11. http://dx.doi.org/10.1108/17515631111106821

Hart, J. \& Spero, J., 1997, The politics of international economic relations, 5th edn. Bedford/St. Martin's Press, New York.

Hawkins, D.B., 2004, 'Competitive intelligence in New Zealand', Journal of Competitive Intelligence and Management 2(4), 42-52.

Heppes, D.W., 2006, An assessment of the level of maturity of the competitive intelligence function within a South African retail bank, MCom mini-dissertation, Department of Business Management, University of Johannesburg, Johannesburg.

Ifan, H-K., Dou Jr, J-M., Manullang, S. \& Dou, H., 2004, 'Developing competitive technical intelligence in Indonesia', Technovation 24(12), 995-999. http://dx.doi. org/10.1016/S0166-4972(03)00069-5
Johnson, A.R., 2004, 'The top 12 priorities for competitive intelligence', viewed 03 December 2013, from http://www.aurorawdc.com/arj_cics_priorities.htm

Kahaner, L., 1996, Competitive intelligence: From black ops to boardrooms: how businesses gather, analyze, and use information to succeed in the global marketplace, Simon \& Schuster, New York, NY.

Kalinowski, D.J., 2012, 'Positioning for growth in emerging markets', Proactive Worldwide 15(3), 10-16, viewed 05 December 2013, from http://www. proactiveworldwide.com/website/media/articles/Growth_in_Emerging Markets-Sept_2012.pdf

Murphy, C., 2005, 'What does the future hold?' in C. Murphy, Competitive intelligence: Gathering, analysing and putting it to work, pp. ix- $\mathrm{xx}$, Gower Publishing Limited, London.

Pellissier, R. \& Kruger, J-P., 2011, 'Understanding the use of strategic intelligence as a strategic management tool in the long-term insurance industry in South Africa', $S A$ Journal of Information Management 13(1), Art. \#426, 13 pages.

Postelnicu, C. \& Ban, I.M., 2010, 'Some empirical approaches of the competitiveness' diamond - the case of Romanian economy', Romanian Economic Journal 13(36), $53-77$.

Prescott, J.E., 1999, 'The evolution of competitive intelligence - designing a process for action', Proposal Management Spring, 37-52.

Sewdass, N., 2012, 'Proposing a competitive intelligence (CI) framework for Public Service departments to enhance service delivery', SA Journal of Information Management 14(1), Art. \#491, 13 pages.

Strategic and Competitive Intelligence Professionals, 2013, 'Code of ethics for $\mathrm{Cl}$ professionals', viewed 01 April 2014, from http://www.scip.org/CodeOfEthics. php

Strauss, A.C. \& Du Toit, A.S.A., 2010, 'Competitive intelligence skills needed to enhance South Africa's competitiveness', Aslib Proceedings 62(3), 302-320. http://dx.doi. org/10.1108/00012531011046925

Viviers, W., Muller, M.L. \& Du Toit, A.S.A., 2005, 'Competitive intelligence: an instrument to enhance competitiveness in South Africa', South African Journal of Economic and Management Sciences 8(2), 246-254.

Viviers, W., Saayman, A. \& Muller, M-L., 2005, 'Enhancing a competitive intelligence culture in South Africa', International Journal of Social Economics 32(7), 576-589. culture in South Africa', International Journal of Soc
http://dx.doi.org/10.1108/03068290510601117

Waheeduzzaman, A.N.M., 2002, 'Competitiveness, human development and inequality: A cross-national comparative inquiry', Competitiveness Review 12(2), 13-29. http://dx.doi.org/10.1108/eb046439

Zikmund, W.G., 2003, Business research methods, 7th edn, Thomson South-Western, Mason, $\mathrm{OH}$ 